\title{
A nomogram to predict arterial bleeding in patients with pelvic fractures after blunt trauma: a retrospective cohort study
}

\author{
Myoung Jun Kim, Jae Gil Lee ${ }^{2}$, Eun Hwa Kim³ and Seung Hwan Lee ${ }^{4^{*}}$ (D)
}

\begin{abstract}
Background: Pelvic bone fractures are one of the biggest challenges faced by trauma surgeons. Especially, the presence of bleeding and hemodynamic instability features is associated with high morbidity and mortality in patients with pelvic fractures. However, prediction of the occurrence of arterial bleeding causing massive hemorrhage in patients with pelvic fractures is difficult. Therefore, the aim of this study was to develop a nomogram to predict arterial bleeding in patients with pelvic bone fractures after blunt trauma.
\end{abstract}

Methods: The medical records of 1404 trauma patients treated between January 2013 and August 2017 were retrospectively reviewed. Patients older than 15 years with a pelvic fracture due to blunt trauma were enrolled $(n=$ 148). The pelvic fracture pattern on anteroposterior radiography was classified according to the Orthopedic Trauma Association/Arbeitsgemeinschaft fur Osteosynthesefragen (OTA/AO) system. Multivariable logistic regression modeling was used to determine the independent risk factors for arterial bleeding. A nomogram was constructed based on the identified risk factors.

Results: The most common pelvic fracture pattern was type A (58.8\%), followed by types B (34.5\%) and C (6.7\%). Of the 148 patients, 28 (18.9\%) showed pelvic arterial bleeding on contrast-enhanced computed tomography or angiography, or in the operative findings. The independent risk factors for arterial bleeding were a type B or C pelvic fracture pattern, body temperature $<36^{\circ} \mathrm{C}$, and serum lactate level $>3.4 \mathrm{mmol} / \mathrm{L}$. A nomogram was developed using these three parameters, along with a systolic blood pressure $<90 \mathrm{mmHg}$. The area under the receiver operating characteristic curve of the predictive model for discrimination was 0.8579 . The maximal Youden index was 0.1527 , corresponding to a cutoff value of 68.65 points, which was considered the optimal cutoff value for predicting the occurrence of arterial bleeding in patients with pelvic bone fractures.

Conclusions: The developed nomogram, which was based on the initial clinical findings identifying risk factors for arterial bleeding, is expected to be helpful in rapidly establishing a treatment plan and improving the prognosis for patients with pelvic bone fractures.

Keywords: Pelvis, Fracture, Nomogram, Hemorrhage

\footnotetext{
* Correspondence: surgeonrumi@gmail.com

${ }^{4}$ Department of Trauma Surgery, Gachon University Gil Medical Center, 21, Namdong-daero 774beon-gil, Namdong-gu, Incheon, Republic of Korea

Full list of author information is available at the end of the article
}

(c) The Author(s). 2021 Open Access This article is licensed under a Creative Commons Attribution 4.0 International License, which permits use, sharing, adaptation, distribution and reproduction in any medium or format, as long as you give appropriate credit to the original author(s) and the source, provide a link to the Creative Commons licence, and indicate if changes were made. The images or other third party material in this article are included in the article's Creative Commons licence, unless indicated otherwise in a credit line to the material. If material is not included in the article's Creative Commons licence and your intended use is not permitted by statutory regulation or exceeds the permitted use, you will need to obtain permission directly from the copyright holder. To view a copy of this licence, visit http://creativecommons.org/licenses/by/4.0/. The Creative Commons Public Domain Dedication waiver (http://creativecommons.org/publicdomain/zero/1.0/) applies to the data made available in this article, unless otherwise stated in a credit line to the data. 


\section{Background}

Pelvic bone fractures can be a significant cause of bleeding and death and are currently among the biggest challenges faced by trauma surgeons $[1,2]$. The mortality rate of patients with a pelvic fracture is $6-14 \%$, and ranges from 54 to $70 \%$ in hemodynamically unstable patients with severe pelvic bone fractures [3-5]. Although in most cases bleeding from pelvic fractures is venous in origin, arterial bleeding is more common in patients with hemodynamic instability or ongoing hemorrhage despite pelvic binding. If pelvic arterial bleeding can be identified early, it can be rapidly treated using angiography and embolization [4]. Therefore, careful evaluation of the presence of bleeding in pelvic ring fractures, as well as its origin, is necessary for adequate management.

However, it is difficult to rapidly identify (or distinguish) the origin of bleeding (whether it is of venous, bone, or arterial origin) following a pelvic fracture. Although recent studies have reported on the predictive factors of arterial bleeding in trauma patients with pelvic bone fractures [3, 6-9], the usefulness of these predictors in a clinical setting remains unclear. Thus, there is a need for a simple and convenient scoring system to predict arterial bleeding in patients with pelvic bone fracture in the initial post-injury period.

Therefore, we investigated the associations between the initial clinical/laboratory findings and pelvic arterial bleeding in patients with pelvic bone fractures after blunt trauma. We hypothesized that a nomogram constructed with the identified risk factors would aid in the early prediction of arterial bleeding caused by a pelvic bone fracture.

\section{Methods}

\section{Patient enrolment and data collection}

Records of consecutive patients aged 15 years or older with traumatic injury who were treated between January 2013 and May 2017 at a single center in an urban setting in Seoul, South Korea, were retrospectively reviewed. This study was approved by the Institutional Review Board of Severance Hospital, Yonsei University Health System (4-2018-0114); the requirement for informed consent was waived because of the retrospective nature of the study.

A total of 1404 trauma patients was admitted to the emergency department during the study period (Fig. 1). Primary and/or secondary surveys were conducted on these patients, according to the advanced trauma life support guidelines [10]. Of the 1404 patients, 268 patients who were managed or evaluated at other hospitals and 973 patients without lesions in the pelvic ring were excluded. Additionally, 3 patients who were referred to another hospital and 12 patients who died within minutes after arrival to the emergency room (ER) were excluded. Thus, 148 patients were enrolled. The patients were divided into groups A and B. Group A comprised of patients with pelvic arterial bleeding evident on contrast-enhanced computed tomography (CT) or angiography or in the operative findings. Group B comprised of patients without evidence of pelvic arterial bleeding.

\section{Clinical variables}

Data collection included the following variables: sex, age, injury mechanism, initial vital signs, Glasgow Coma Scale (GCS) score, current medication, Abbreviated

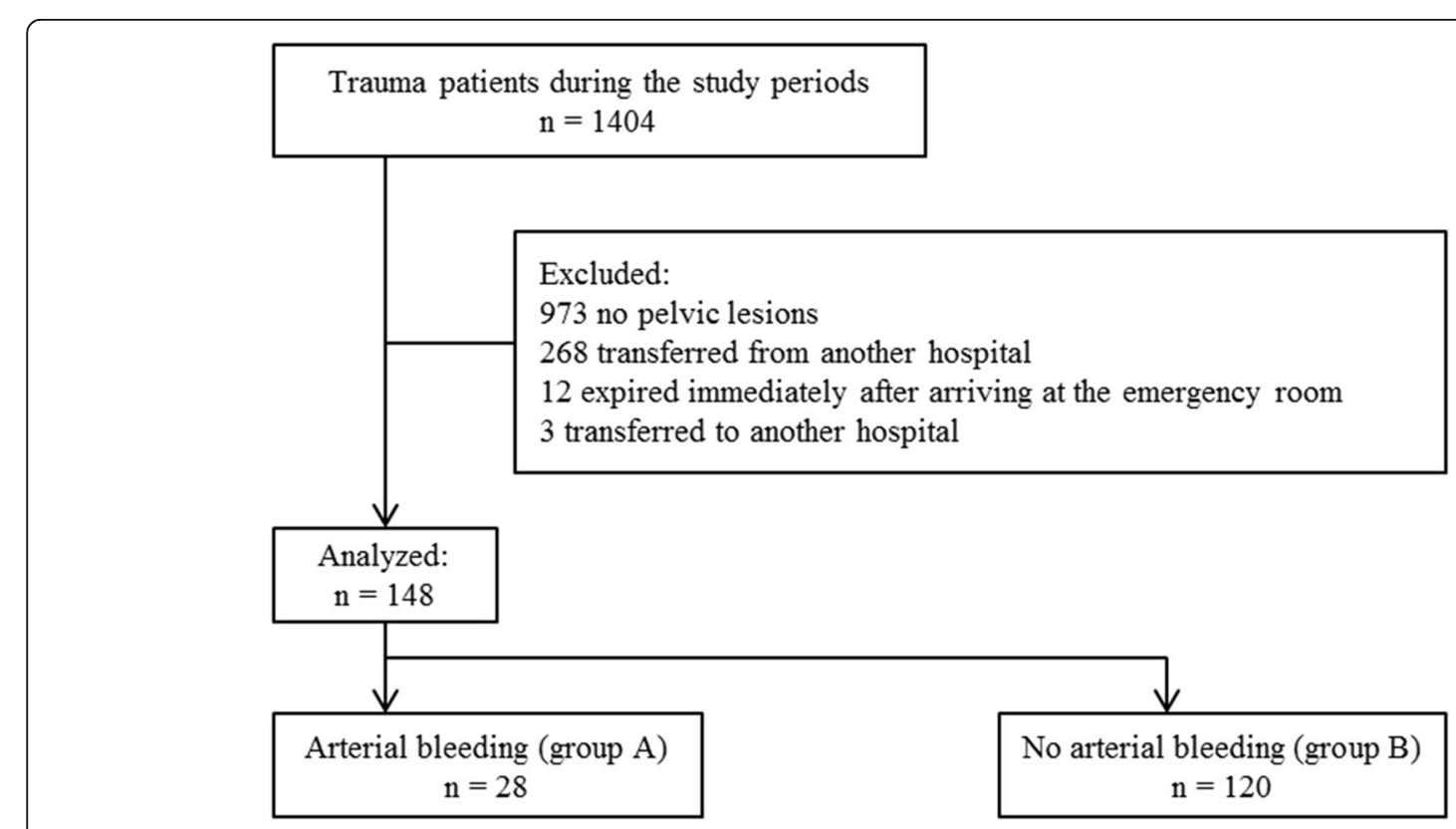

Fig. 1 Patient selection flowchart 
Injury Scale (AIS) score, Injury Severity Score (ISS), Revised Trauma Score (RTS), Trauma and Injury Severity Score (TRISS), Acute Physiology and Chronic Health Evaluation (APACHE) II score, and initial arterial blood values, including the serum lactate level. Additionally, using anteroposterior (AP) pelvic radiographs, the pelvic fracture pattern was classified as type A, B, or C, in accordance with the Orthopedic Trauma Association/ Arbeitsgemeinschaft fur Osteosynthesefragen (OTA/ AO) system [see Additional file 1]. The fracture pattern classification was on the basis of the findings of the trauma and orthopedic surgeons and was additionally confirmed by the surgical and radiological records.

\section{Statistical analysis and model construction}

Continuous variables are expressed as means \pm standard deviations or as medians and interquartile ranges (depending on the data distribution) and were evaluated using the Student $t$ test or Mann-Whitney $U$ test, as appropriate. Categorical variables are expressed as numbers (\%) and were evaluated using the chi-square test or Fisher's exact test, as appropriate. Univariable logistic regression analyses were performed to identify the factors associated with the risk of arterial bleeding. A multivariable logistic regression analysis was conducted using variables with clinical meaning and/or statistical significance in the univariable analyses. A nomogram was constructed based on the results of the multivariable logistic regression analysis. The nomogram was internally validated for discrimination and calibration via bootstrapping (500 resamples) [11]. The area under the receiver operating characteristic (ROC) curve (AUC) was used to assess the predictive accuracy of the model. The relationship between the observed probability of arterial bleeding and the predicted probability was graphically assessed using a calibration plot. To improve the clinical practicality of the nomogram, we assigned cutoff values for continuous variables, derived from the Youden index [12]. The accuracy of the optimal cutoff value was assessed by the sensitivity, specificity, predictive values, and likelihood ratios. All statistical tests were 2-sided, and $P$ values less than 0.05 were considered statistically significant. The analyses were performed using SAS version 9.4 (SAS Institute Inc., Cary, NC, USA) and the R version 3.4 software (http://www.r-project.org/) with the "rms" package, which was used to construct the nomogram.

\section{Results}

\section{Baseline characteristics}

The baseline characteristics of the patients are shown in Table 1. Among the 148 patients, 28 patients (18.9\%) had arterial bleeding (group A) and 120 patients (81.1\%) did not have arterial bleeding (group B). The most common mechanism of injury was being struck by a motor vehicle as a pedestrian (39.9\%), followed by falls (35.8\%), motorcycle crashes (15.5\%), motor vehicle crashes $(6.1 \%)$, and other mechanisms $(2.7 \%)$. The overall in-hospital mortality rate was $5.4 \%$, and the inhospital mortality rate was significantly higher in group A than in group B $(32.1 \%$ vs. $7.5 \%, P=0.001)$.

\section{Initial clinical and laboratory variables}

Initial clinical and laboratory variables were compared between the two groups (Table 2). Significant group differences were found for the following variables: a systolic blood pressure $(\mathrm{SBP})<90 \mathrm{mmHg}$, heart rate $(\mathrm{HR})>120$ bpm, body temperature $(\mathrm{BT})<36^{\circ} \mathrm{C}$, serum lactate level $>3.4 \mathrm{mmol} / \mathrm{L}$, and base deficit $<-6 \mathrm{mmol} / \mathrm{L}$. According to the classification of the posterior pelvic ring stability using the OTA/AO system, the most common fracture pattern in group A was type B, with partial instability $(n$ $=14,50.0 \%)$, followed by types $\mathrm{A}(n=7,25.0 \%)$ and $\mathrm{C}$ $(n=7,25.0 \%)$. Type A $(n=80,66.7 \%)$ was the most common fracture pattern in group B, followed by types B $(n=37,30.8 \%)$ and C $(n=3,2.5 \%)$, with a significant group difference in the fracture pattern distribution $(P<$ $0.001)$.

\section{Univariable and multivariable logistic regression analyses for the risk factors for pelvic arterial bleeding}

The results of the univariable and multivariable logistic regression analyses are presented in Table 3 . The multivariable analysis revealed type $B$ (odds ratio $[\mathrm{OR}]=$ $3.404,95 \%$ confidence interval $[\mathrm{CI}]=1.116-10.384, P=$ $0.031)$ and type $C$ fracture patterns $(\mathrm{OR}=22.534,95 \%$ $\mathrm{CI}=3.606-140.804, P=0.001)$ as independent risk factors for pelvic arterial bleeding. Among the initial clinical and laboratory variables, $\mathrm{BT}<36^{\circ} \mathrm{C}(\mathrm{OR}=8.757$, 95\% CI $=2.718-28.216, P<0.001)$ and a serum lactate $>3.4 \mathrm{mmol} / \mathrm{L}(\mathrm{OR}=4.589,95 \% \mathrm{CI}=1.354-15.552, P=$ 0.014 ) were revealed as independent risk factors for pelvic arterial bleeding.

\section{Development and validation of a nomogram for predicting pelvic arterial bleeding}

A nomogram to predict pelvic arterial bleeding was developed using the identified independent risk factors for pelvic arterial bleeding (pelvic bone fracture pattern, BT, and serum lactate level) and SBP, as this parameter is considered clinically important (Fig. 2). The overall predictive accuracy of the model incorporating these four variables was good, with an AUC of 0.8579 (95\% CI = 0.7814-0.9343) (Fig. 3). Additionally, the calibration plot in the internal validation demonstrated a good correlation between the observed probability of arterial bleeding and the predicted probability, as assessed in a 
Table 1 Baseline characteristics of patients

\begin{tabular}{|c|c|c|c|}
\hline Variable & Group A $(n=28)$ (arterial bleeding) & Group B $(n=120)$ (no arterial bleeding) & $P$ value \\
\hline Age (years) & $57.5(30.5,74.0)$ & $49.5(33.0,65.0)$ & 0.426 \\
\hline Sex & & & 0.342 \\
\hline Male & $16(57.1)$ & $80(66.7)$ & \\
\hline Female & $12(42.9)$ & $40(33.3)$ & \\
\hline \multicolumn{4}{|l|}{ Medications } \\
\hline Aspirin & $2(7.1)$ & $3(2.5)$ & 0.239 \\
\hline Clopidogrel & $1(3.6)$ & $2(1.7)$ & 0.469 \\
\hline Warfarin & $0(0)$ & $2(1.7)$ & $>0.999$ \\
\hline Injury mechanism & & & 0.191 \\
\hline Pedestrian struck by a motor vehicle & $14(50.0)$ & $45(37.5)$ & \\
\hline Motor vehicle crashes & $0(0)$ & $9(7.5)$ & \\
\hline Motorcycle crashes & $3(10.7)$ & $20(16.7)$ & \\
\hline Falls & $9(32.1)$ & $44(36.7)$ & \\
\hline Others & $2(7.1)$ & $2(1.7)$ & \\
\hline \multicolumn{4}{|l|}{ AIS } \\
\hline Head and neck & $2(0,2.0)$ & $1(0,2.0)$ & 0.619 \\
\hline Face & $0(0,0)$ & $0(0,1.0)$ & 0.008 \\
\hline Chest & $2(0,3.0)$ & $0(0,3.0)$ & 0.408 \\
\hline Abdomen & $3(0,3.0)$ & $0(0,2.0)$ & 0.001 \\
\hline Extremities & $4(2.5,4.0)$ & $2(2.0,3.0)$ & $<0.001$ \\
\hline External & $1(1.0,1.0)$ & $1(0.5,1.0)$ & 0.213 \\
\hline GCS score & $15.0(12.0,15.0)$ & $15.0(14.0,15.0)$ & 0.203 \\
\hline ISS & $28(18.0,34.0)$ & $15.5(9.0,25.0)$ & 0.001 \\
\hline RTS & $6.64(5.44,7.84)$ & $7.84(7.11,7.84)$ & 0.006 \\
\hline TRISS & $88.2(57.09,95.94)$ & $96.75(89.0,99.25)$ & 0.001 \\
\hline APACHE ॥ & $23.0 \pm 12.9$ & $15.7 \pm 8.2$ & 0.005 \\
\hline In-hospital mortality & $9(32.1)$ & $9(7.5)$ & 0.001 \\
\hline
\end{tabular}

Values are presented as mean $\pm S D$, median (interquartile range), or $n$ (\%)

AIS Abbreviated Injury Scale, ISS Injury Severity Score, RTS Revised Trauma Score, TRISS Trauma and Injury Severity Score, APACHE Acute Physiology and Chronic Health Evaluation, GCS Glasgow Coma Scale

Table 2 Initial clinical and laboratory findings

\begin{tabular}{llll}
\hline Variable & Group A $(\boldsymbol{n}=\mathbf{2 8})$ (arterial bleeding) & Group B $(\boldsymbol{n}=\mathbf{1 2 0})$ (no arterial bleeding) & $\boldsymbol{P}$ value \\
\hline $\mathrm{SBP}<90 \mathrm{mmHg}$ & $13(46.4)$ & $22(18.3)$ & 0.002 \\
Heart rate $>120 \mathrm{bpm}$ & $4(14.3)$ & $11(9.2)$ & 0.419 \\
$\mathrm{BT}<36^{\circ} \mathrm{C}$ & $14(50.0)$ & $19(15.8)$ & $<0.001$ \\
$\mathrm{GCS} \mathrm{score}$ & $15.00(14.00,15.00)$ & $15.00(12.00,15.00)$ & 0.203 \\
Lactate $>3.4 \mathrm{mmol} / \mathrm{L}$ & $17(60.7)$ & $32(26.7)$ & $15(12.5)$ \\
Base deficit $<-6 \mathrm{mmol} / \mathrm{L}$ & $10(35.7)$ & & 0.001 \\
Pelvic fracture pattern & & $80(66.7)$ & 0.003 \\
A & $7(25.0)$ & $37(30.8)$ \\
B & $14(50.0)$ & $3(2.5)$ \\
$\mathrm{C}$ & $7(25.0)$ & & \\
\hline
\end{tabular}

Values are presented median (interquartile range) or $n(\%)$ 
Table 3 Univariable and multivariable logistic regression analyses of the risk factors for pelvic arterial bleeding

\begin{tabular}{|c|c|c|c|c|}
\hline \multirow[t]{2}{*}{ Variable } & \multicolumn{2}{|l|}{ Univariable analysis } & \multicolumn{2}{|l|}{ Multivariable analysis } \\
\hline & OR $(95 \% \mathrm{Cl})$ & $P$ value & OR $(95 \% \mathrm{Cl})$ & $P$ value \\
\hline $\mathrm{SBP}<90 \mathrm{mmHg}$ & 3.861 (1.610-9.260) & 0.002 & $1.338(0.352-5.078)$ & 0.669 \\
\hline Heart rate $>120$ bpm & $1.652(0.484-5.632)$ & 0.423 & & \\
\hline $\mathrm{BT}<36^{\circ} \mathrm{C}$ & $5.316(2.187-12.922)$ & $<0.001$ & 8.757 (2.718-28.216) & $<0.001$ \\
\hline GCS score & $0.964(0.876-1.062)$ & 0.463 & & \\
\hline Lactate $>3.4 \mathrm{mmol} / \mathrm{L}$ & $4.250(1.799-10.039)$ & 0.001 & 4.589 (1.354-15.552) & 0.014 \\
\hline Base deficit $<-6 \mathrm{mmol} / \mathrm{L}$ & 3.889 (1.514-9.991) & 0.005 & $1.263(0.303-5.259)$ & 0.749 \\
\hline \multicolumn{5}{|l|}{ Pelvic fracture pattern } \\
\hline A & Ref. & & & \\
\hline B & $4.324(1.611-11.608)$ & 0.004 & $3.404(1.116-10.384)$ & 0.031 \\
\hline C & $26.667(5.617-126.596)$ & $<0.001$ & $22.534(3.606-140.804)$ & 0.001 \\
\hline
\end{tabular}

OR odds ratio, $C l$ confidence interval, SBP systolic blood pressure, BPM beats per minute, $B T$ body temperature, GCS Glasgow coma scale

bootstrap-corrected ROC curve (AUC $=0.8712,95 \%$ CI $=0.7880-0.9373$ ) (Fig. 4).

\section{Risk of pelvic arterial bleeding based on the nomogram score}

The optimal cutoff value of the total nomogram score was 68.65, which had a maximal Youden index of 0.1527 . Using a cutoff of $>68.65$, the nomogram had a sensitivity of $78.6 \%$, specificity of $78.3 \%$, positive predictive value of $45.8 \%$, and negative predictive value of 94.0\% (Table 4).

\section{Discussion}

In the past decade, several studies have investigated the risk factors predicting pelvic hemorrhage following pelvic injury [6-9, 13-19]; however, controversy remains regarding whether each risk factor is sufficient and adequately convenient to allow the rapid identification of the origin of pelvic bleeding in the acute trauma setting. A rapid and accurate diagnosis and management of pelvic bleeding is critical for the optimization of patient survival [20-22]. Unfortunately, the early identification of hemorrhage in patients with pelvic fractures is often

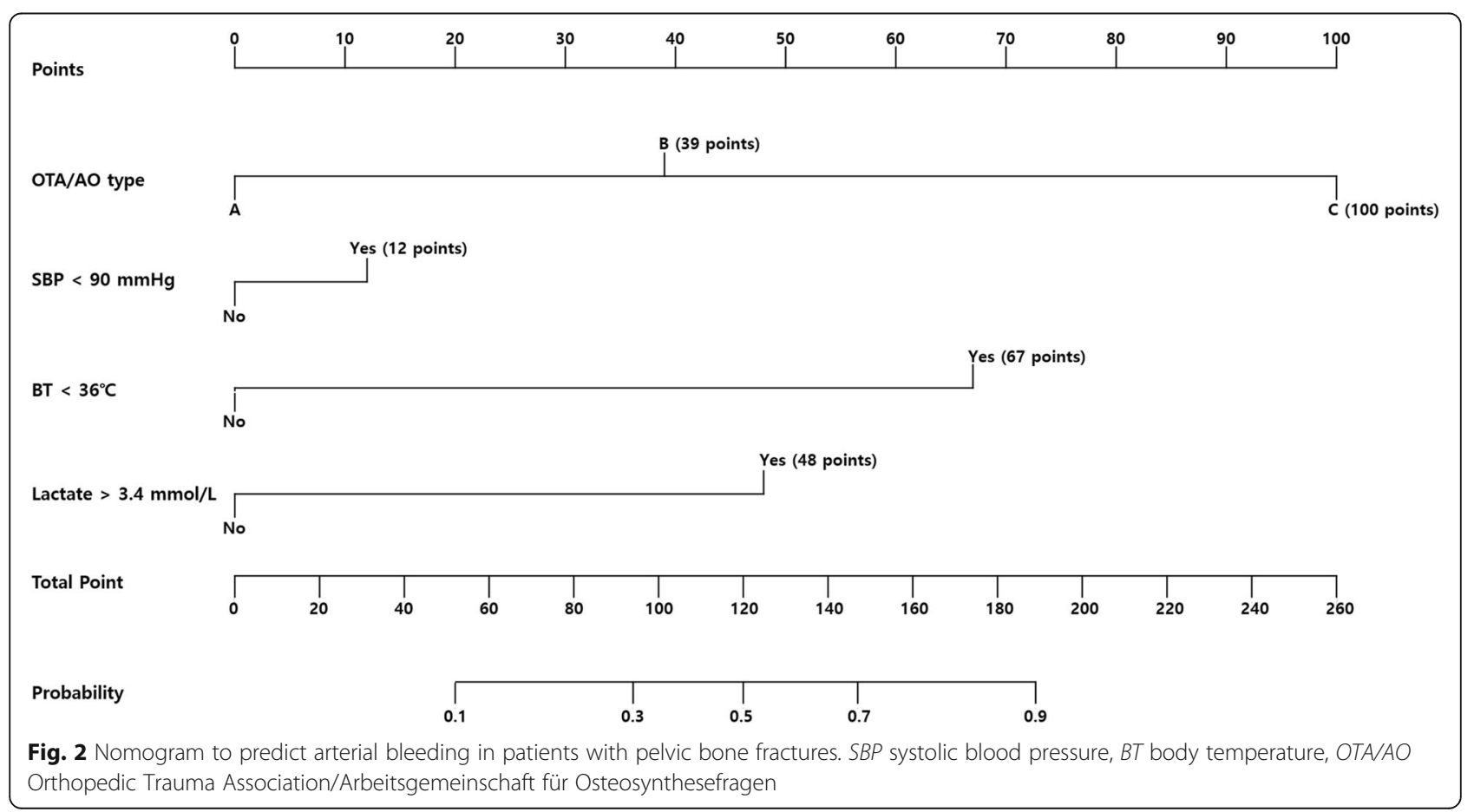




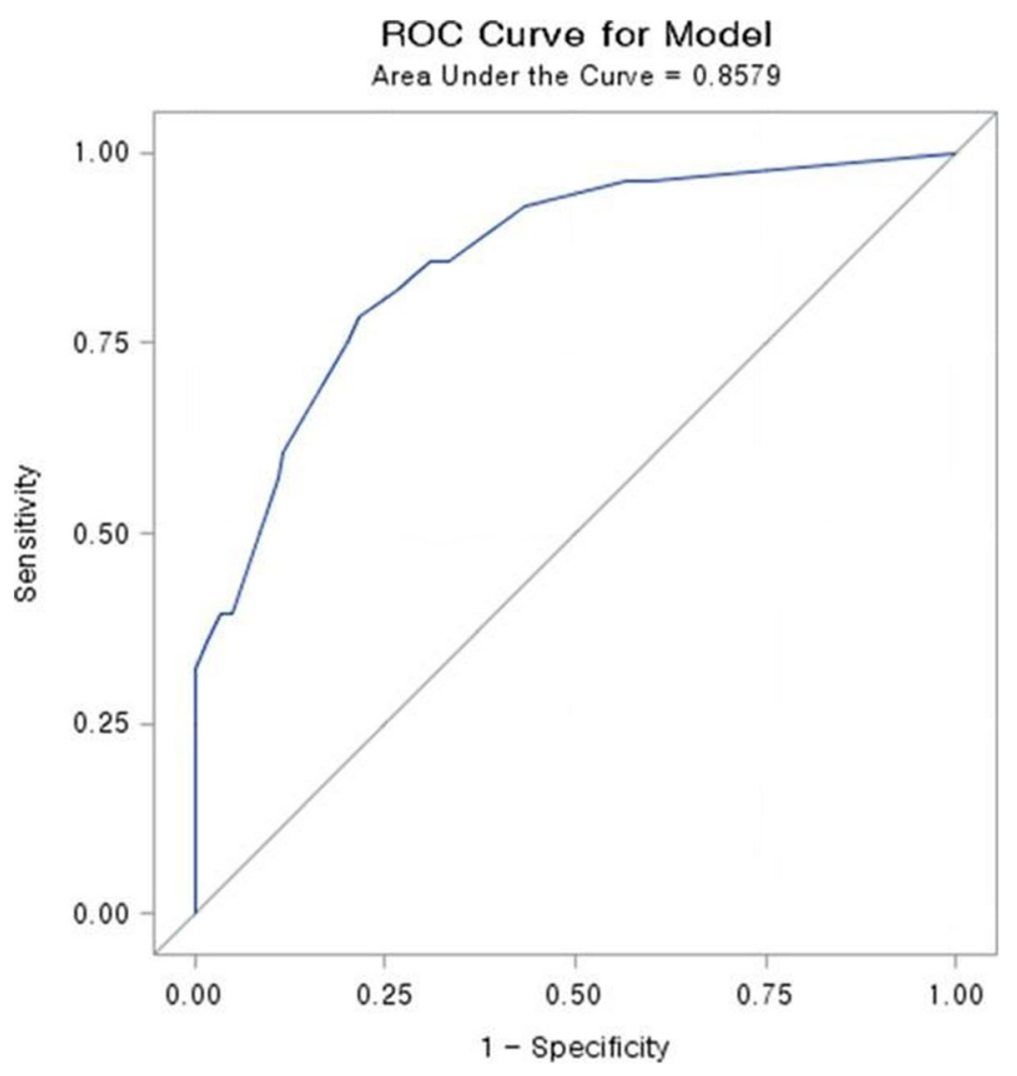

Fig. 3 Receiver operating characteristic (ROC) curves for the predictive model

difficult. Delays in the recognition and treatment of pelvic bleeding result in the progression from compensated reversible shock to multiple organ failure, and eventually, death. Particularly, unstable pelvic fractures caused by a high-energy injury may lead to severe bleeding and irreversible hemorrhagic shock [23, 24].

In the present study, we investigated the associations between pelvic arterial bleeding and the initial laboratory and clinical findings, including the pelvic bone fracture pattern on AP pelvic radiography, performed during an initial visit to the ER after trauma. A pelvic fracture pattern of type B or type $\mathrm{C}, \mathrm{BT}<36^{\circ} \mathrm{C}$, and serum lactate level $>3.4 \mathrm{mmol} / \mathrm{L}$ were identified as independent risk factors for pelvic arterial bleeding after pelvic trauma. Moreover, we developed a nomogram to predict early pelvic arterial bleeding, based on the three identified independent risk factors and SBP < $90 \mathrm{mmHg}$. The nomogram demonstrated good accuracy in estimating the risk of pelvic arterial bleeding. In addition, the nomogram was internally validated and showed good performance in terms of calibration and discrimination.

Previous studies have shown that unstable pelvic fractures are associated with hemodynamic instability [6, 14-19]. Unstable pelvic fractures are known to be accompanied by major ligament disruptions and are significantly associated with the occurrence of pelvic fracture-related arterial bleeding and the need for pelvic embolization [7, 17-19]. Furthermore, a previous study reported that a pelvic fracture pattern with major ligament disruption, such as the sacroiliac ligament, is an independent risk factor for pelvic arterial bleeding [3]. In the OTA/AO classification system, type B and type C fractures, as unstable pelvic fractures, are more likely to be associated with vascular injuries than are type A fractures. Consistent with this, the present study revealed type $\mathrm{B}$ and type $\mathrm{C}$ fractures (according to the OTA/AO system) as independent risk factors for pelvic arterial bleeding in patients with blunt pelvic trauma. We used OTA/AO classification rather than Young-Burgess classification, as the OTA/OA system is easier use with pelvic $\mathrm{AP}$ radiographs and better reflects the hemodynamic status [14-16].

Hypothermia inhibits coagulation protease activity and platelet function [25, 26]. Mortality from traumatic hemorrhage is markedly increased in severe hypothermia when core temperatures fall below $32^{\circ} \mathrm{C}$ [27]. Furthermore, clinically significant effects on plasma coagulation, platelet function, and clinical bleeding are seen in moderate hypothermia at temperatures below $34{ }^{\circ} \mathrm{C}$ [25-32] . However, a BT of less than $36^{\circ} \mathrm{C}$ was significantly associated with pelvic arterial bleeding after pelvic ring 


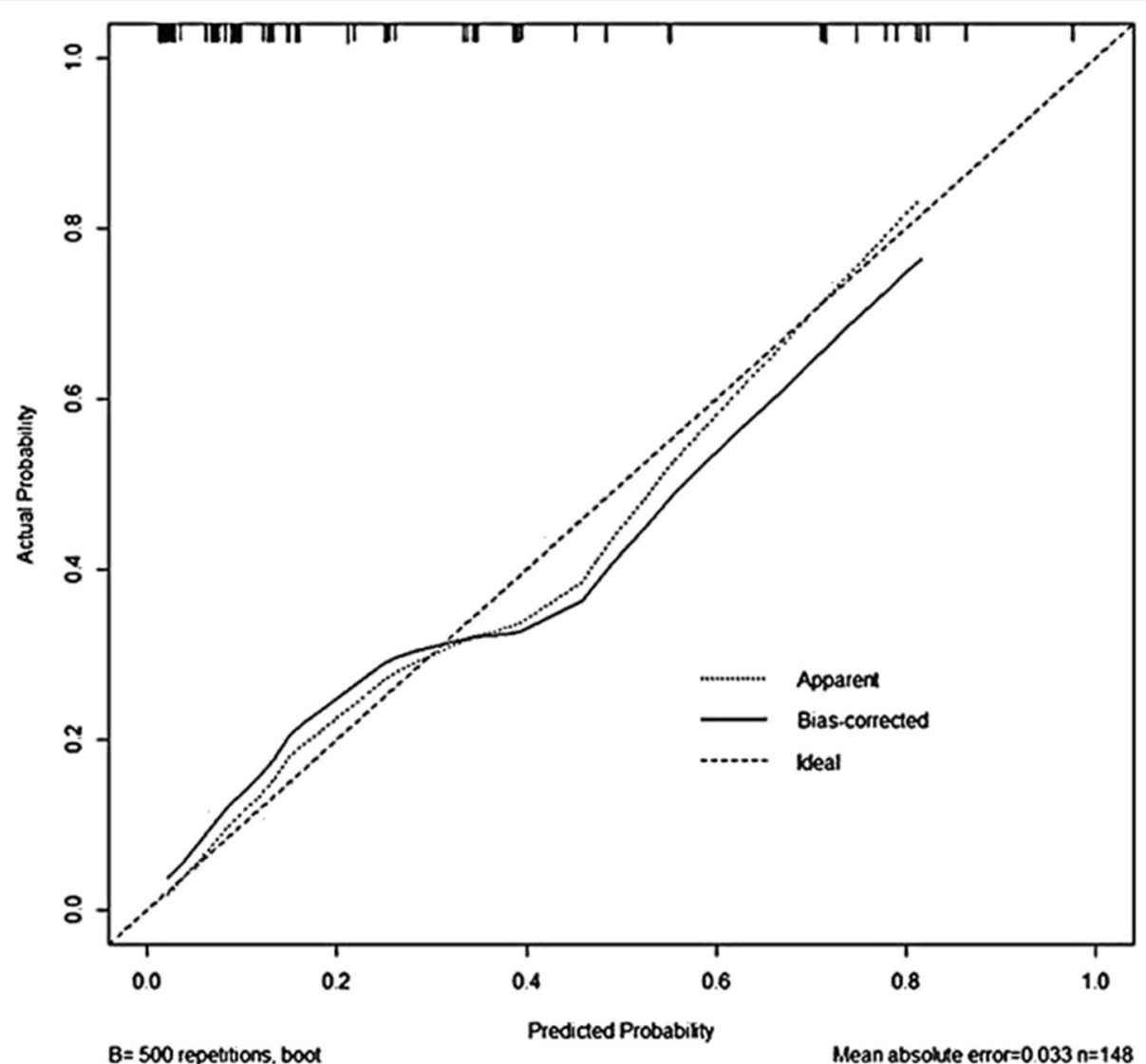

Fig. 4 Calibration plot in the internal validation

fractures in the present study. Although a $\mathrm{BT}<36{ }^{\circ} \mathrm{C}$ had the highest points in the nomogram, hypothermia alone did not meet the scoring criteria for the prediction of pelvic arterial bleeding. Similarly, the other parameters in the nomogram, with the exception of a type $\mathrm{C}$ fracture, failed to meet the scoring criteria when considered alone. Therefore, it is necessary to simultaneously consider various risk factors to improve the prediction of pelvic arterial bleeding.

Table 4 Accuracy of the nomogram score in the estimation of the risk of pelvic arterial bleeding

\begin{tabular}{ll}
\hline Variable & Value (95\% Cl) \\
\hline Area under ROC curve, concordance index & $0.8579(0.7814-0.9343)$ \\
Cutoff score & 68.65 \\
Sensitivity, \% & $78.6(60.5-89.8)$ \\
Specificity, \% & $78.3(70.1-84.8)$ \\
Positive predictive value, \% & $45.8(32.6-59.7)$ \\
Negative predictive value, \% & $94.0(85.5-97.2)$ \\
Positive likelihood ratio & $3.622(2.452-5.363)$ \\
Negative likelihood ratio & $0.273(0.134-0.559)$ \\
\hline
\end{tabular}

$\mathrm{ROC}$ receiver operating curve, $\mathrm{Cl}$ confidence interval
Recent clinical guidelines recommend measuring the serum lactate level or base deficit as a sensitive test to monitor the degree of bleeding and shock [22, 33, 34]. The amount of lactic acid produced by anaerobic decomposition is an indirect indicator of oxygen debt, tissue low perfusion, and hemorrhagic shock. Furthermore, previous studies have demonstrated that an increased serum lactate level is associated with pelvic bleeding caused by pelvic trauma $[8,35]$. Consistent with this, the present study revealed a serum lactate level $>3.4 \mathrm{mmol} /$ $\mathrm{L}$ as an independent risk factor of arterial bleeding in blunt trauma patients with pelvic bone fractures.

In general, it is accepted that trauma patients with SBP $<90 \mathrm{mmHg}$ are in hypotension. Recent studies have suggested that initial SBP in the range of $90-110 \mathrm{mmHg}$, or less, in a trauma patient may be indicative of hypoperfusion and is associated with poor patient outcomes [3, 9, 13, 36, 37]. Although different SBP cutoff values were utilized, previous studies have reported that decreased SBP is an independent risk factor of arterial bleeding in patients with pelvic bone fractures [3, 9, 13]. In the present study, univariate analysis revealed that patients with and without arterial bleeding had significant differences in the frequency of SBP $<90 \mathrm{mmHg}$. 
However, SBP $<90 \mathrm{mmHg}$ was not identified as a significant independent risk factor in multivariable analysis. Despite this, we included SBP $<90 \mathrm{mmHg}$ in the parameters of the nomogram, given its proven clinical significance $[9,36,37]$, which resulted in the unabated good predictability of the nomogram.

To the best of our knowledge, no study has assessed the risk of arterial bleeding in patients with pelvic bone fractures using a nomogram. This nomogram can be easily and quickly used to predict the occurrence of arterial bleeding in the acute management stage in patients with pelvic bone fractures. Based on the present study data, we suggest that a nomogram score of greater than 68.65 points during the initial assessment of patients with pelvic bone fractures after blunt trauma necessitates the preparation for the control of pelvic arterial bleeding. However, there are some important issues to consider before using the nomogram. The clinical use of the model requires pelvic fractures to be diagnosed as a type $\mathrm{A}, \mathrm{B}$, or $\mathrm{C}$ fracture via AP pelvic radiographs. Additionally, although pelvic arterial bleeding can occur in all pelvic fracture patterns and occurred in $25 \%$ of patients with type A fracture in group A, "fracture type A" was used as the reference, given its stability and hemodynamic status. Furthermore, other sources of bleeding (beyond pelvic bleeding) should be considered as another potential cause of hemorrhagic shock in patients with multiple traumas. Furthermore, at least 1 in 10 patients with pelvic bone fractures and arterial bleeding may be potentially missed (sensitivity, 0.786; negative predictive value, 0.94 ) with the rigid application of the nomogram. Therefore, the nomogram results should be carefully interpreted and used strictly in wider context of the patient's clinical condition, clinical setting, individual-included factors, and factors not included in the nomogram.

The present study has some limitations. First, the present study was retrospective in nature. Second, the present study analysis was based on data from a single institution, and the study population was relatively small. Therefore, it may be difficult to generalize the study results. Third, our calibration plot was only validated internally. Thus, we are planning a prospective study to validate the model externally.

\section{Conclusions}

We developed a nomogram to predict the risk of arterial bleeding in patients with pelvic bone fractures. This nomogram consists of reliable parameters, and it can aid physicians by allowing easier and more rapid decisionmaking in the management of patients with pelvic bone fractures after blunt trauma. However, this nomogram should be validated in a prospective, multicenter randomized study.

\section{Supplementary Information}

The online version contains supplementary material available at https://doi. org/10.1186/s13018-021-02247-2.

Additional file 1. OTA/AO classification of pelvic fracture. OTA/AO Orthopedic Trauma Association/Arbeitsgemeinschaft für

Osteosynthesefragen

\begin{abstract}
Abbreviations
AIS: Abbreviated Injury Scale; APACHE: Acute Physiology and Chronic Health Evaluation; AUC: Area under the receiver operating characteristic curve; BT: Body temperature; Cl: Confidence interval; CT: Computed tomography; ER: Emergency room; GCS: Glasgow Coma Scale; HR: Heart rate; ISS: Injury Severity Score; OR: Odds ratio; OTA/AO: Orthopedic Trauma Association/ Arbeitsgemeinschaft für Osteosynthesefragen; ROC: Receiver operating curve; RTS: Revised Trauma Score; SBP: Systolic blood pressure; TRISS: Trauma and Injury Severity Score
\end{abstract}

\section{Acknowledgements \\ The authors thank YH Roh for providing assistance with the statistical analyses, and we thank all the coordinators for their valuable help and cooperation.}

\section{Authors' contributions}

SHL designed the study. MJK and SHL were responsible for data acquisition. SHL, MJK, and EHK analyzed and interpreted the data with JGL. MJK and EHK wrote the article. All authors read and approved the final manuscript.

\section{Funding}

This research did not receive any specific grant from funding agencies in the public, commercial, or not-for-profit sectors.

\section{Availability of data and materials}

The datasets used and/or analyzed during the current study are available from the corresponding author on reasonable request.

\section{Ethics approval and consent to participate}

The study was approved by the Institutional Review Board of Severance Hospital, Yonsei University Health System (4-2018-0114); the requirement for informed consent was waived because of the retrospective nature of the study.

\section{Consent for publication}

Not applicable.

\section{Competing interests}

The authors declare that they have no competing interests.

\section{Author details}

${ }^{1}$ Department of Surgery, Yonsei University Wonju College of Medicine, Wonju Severance Christian Hospital, Wonju, Republic of Korea. ${ }^{2}$ Department of Surgery, Yonsei University College of Medicine, Seoul, Republic of Korea. ${ }^{3}$ Biostatistics Collaboration Unit, Yonsei University College of Medicine, Seoul, Republic of Korea. ${ }^{4}$ Department of Trauma Surgery, Gachon University Gil Medical Center, 21, Namdong-daero 774beon-gil, Namdong-gu, Incheon, Republic of Korea.

Received: 26 November 2020 Accepted: 18 January 2021 Published online: 08 February 2021

\section{References}

1. Magnone S, Coccolini F, Manfredi R, Piazzalunga D, Agazzi R, Arici C, et al. Management of hemodynamically unstable pelvic trauma: results of the first Italian consensus conference (cooperative guidelines of the Italian Society of Surgery, the Italian Association of Hospital Surgeons, the Multi-specialist Italian Society of Young Surgeons, the Italian Society of Emergency Surgery and Trauma, the Italian Society of Anesthesia, Analgesia, Resuscitation and Intensive Care, the Italian Society of Orthopaedics and Traumatology, the Italian Society of Emergency Medicine, the Italian Society of Medical 
Radiology -Section of Vascular and Interventional Radiology- and the World Society of Emergency Surgery). World J Emerg Surg. 2014;9:18.

2. Verbeek DO, Sugrue M, Balogh Z, Cass D, Civil I, Harris I, et al. Acute management of hemodynamically unstable pelvic trauma patients: time for a change? Multicenter review of recent practice. World J Surg. 2008;32: 1874-82.

3. Salim A, Teixeira PG, DuBose J, Ottochian M, Inaba K, Margulies DR, et al. Predictors of positive angiography in pelvic fractures: a prospective study. J Am Coll Surg. 2008;207:656-62.

4. Kos S, Gutzeit A, Hoppe H, Liu DM, Jacob AL. Diagnosis and therapy of acute hemorrhage in patients with pelvic fractures. Semin Musculoskelet Radiol. 2013;17:396-406.

5. Gruen GS, Leit ME, Gruen RJ, Peitzman AB. The acute management of hemodynamically unstable multiple trauma patients with pelvic ring fractures. J Trauma. 1994:36(5):706-11 discussion 11-3.

6. Blackmore CC, Cummings P, Jurkovich GJ, Linnau KF, Hoffer EK, Rivara FP. Predicting major hemorrhage in patients with pelvic fracture. J Trauma. 2006;61:346-52.

7. Manson TT, Nascone JW, Sciadini MF, O'Toole RV. Does fracture pattern predict death with lateral compression type 1 pelvic fractures? J Trauma. 2010;69:876-9.

8. Ohmori T, Matsumoto T, Kitamura T, Tamura R, Tada K, Inoue T, et al. Scoring system to predict hemorrhage in pelvic ring fracture. Orthop Traumatol Surg Res. 2016;102:1023-8.

9. Miller PR, Moore PS, Mansell E, Meredith JW, Chang MC. External fixation or arteriogram in bleeding pelvic fracture: initial therapy guided by markers of arterial hemorrhage. J Trauma. 2003;54:437-43.

10. ATLS subcommittee; American College of Surgeons' Committee on Trauma; International ATLS working group; Advanced trauma life support (ATLS): the ninth edition. J Trauma Acute Care Surg. 2013;74:1363-6.

11. Harrell FE Jr, Lee KL, Mark DB. Multivariable prognostic models: issues in developing models, evaluating assumptions and adequacy, and measuring and reducing errors. Stat Med. 1996;15:361-87.

12. Youden WJ. Index for rating diagnostic tests. Cancer. 1950;3:32-5.

13. Toth L, King KL, McGrath B, Balogh ZJ. Factors associated with pelvic fracture-related arterial bleeding during trauma resuscitation: a prospective clinical study. J Orthop Trauma. 2014;28:489-95.

14. Theumann NH, Verdon JP, Mouhsine E, Denys A, Schnyder P, Portier F. Traumatic injuries: imaging of pelvic fractures. Eur Radiol. 2002;12:1312-30.

15. Osterhoff G, Scheyerer MJ, Fritz Y, Bouaicha S, Wanner GA, Simmen HP, et al. Comparing the predictive value of the pelvic ring injury classification systems by Tile and by Young and Burgess. Injury. 2014;45:742-7.

16. Slater SJ, Barron DA. Pelvic fractures-a guide to classification and management. Eur J Radiol. 2010;74:16-23.

17. Hamill J, Holden A, Paice R, Civil I. Pelvic fracture pattern predicts pelvic arterial haemorrhage. Aust N Z J Surg. 2000;70:338-43.

18. Metz CM, Hak DJ, Goulet JA, Williams D. Pelvic fracture patterns and their corresponding angiographic sources of hemorrhage. Orthop Clin North Am. 2004;35:431-7 v.

19. Costantini TW, Coimbra R, Holcomb JB, Podbielski JM, Catalano RD, Blackburn A, et al. Pelvic fracture pattern predicts the need for hemorrhage control intervention-results of an AAST multi-institutional study. J Trauma Acute Care Surg. 2017;82:1030-8.

20. Heetveld MJ, Harris I, Schlaphoff G, Sugrue M. Guidelines for the management of haemodynamically unstable pelvic fracture patients. ANZ J Surg. 2004;74:520-9.

21. Tile M. Pelvic ring fractures: should they be fixed? J Bone Joint Surg Br. 1988;70:1-12.

22. Coccolini F, Stahel PF, Montori G, Biffl W, Horer TM, Catena F, et al. Pelvic trauma: WSES classification and guidelines. World J Emerg Surg. 2017;12:5.

23. Smith W, Williams A, Agudelo J, Shannon M, Morgan S, Stahel P, et al. Early predictors of mortality in hemodynamically unstable pelvis fractures. J Orthop Trauma. 2007:21:31-7.

24. Manson T, O'Toole RV, Whitney A, Duggan B, Sciadini M, Nascone J. YoungBurgess classification of pelvic ring fractures: does it predict mortality, transfusion requirements, and non-orthopaedic injuries? J Orthop Trauma. 2010;24:603-9

25. Reed RL 2nd 1, Bracey AW Jr., Hudson JD, Miller TA, Fischer RP. Hypothermia and blood coagulation: dissociation between enzyme activity and clotting factor levels. Circ Shock. 1990;32:141-52.
26. Wolberg AS, Meng ZH, Monroe DM 3rd, Hoffman M. A systematic evaluation of the effect of temperature on coagulation enzyme activity and platelet function. J Trauma. 2004;56:1221-8.

27. Cosgriff N, Moore EE, Sauaia A, Kenny-Moynihan M, Burch JM, Galloway B. Predicting life-threatening coagulopathy in the massively transfused trauma patient: hypothermia and acidoses revisited. J Trauma. 1997;42:857-61 discussion 861-2.

28. Peng RY, Bongard FS. Hypothermia in trauma patients. J Am Coll Surg. 1999, 188:685-96.

29. Watts DD, Trask A, Soeken K, Perdue P, Dols S, Kaufmann C. Hypothermic coagulopathy in trauma: effect of varying levels of hypothermia on enzyme speed, platelet function, and fibrinolytic activity. J Trauma. 1998:44:846-54.

30. Gentilello LM, Jurkovich GJ, Stark MS, Hassantash SA, O'Keefe GE. Is hypothermia in the victim of major trauma protective or harmful? A randomized, prospective study. Ann Surg. 1997:226:439-47 discussion 47-9.

31. Meng ZH, Wolberg AS, Monroe DM 3rd, Hoffman M. The effect of temperature and $\mathrm{pH}$ on the activity of factor Vlla: implications for the efficacy of high-dose factor Vlla in hypothermic and acidotic patients. J Trauma. 2003;55:886-91.

32. Martini WZ, Pusateri AE, Uscilowicz JM, Delgado AV, Holcomb JB. Independent contributions of hypothermia and acidosis to coagulopathy in swine. J Trauma. 2005:58:1002-9 discussion 1009-10.

33. Rhodes A, Evans LE, Alhazzani W, Levy MM, Antonelli M, Ferrer R, et al. Surviving sepsis campaign: international guidelines for management of sepsis and septic shock: 2016. Intensive Care Med. 2017;43:304-77.

34. Spahn DR, Bouillon B, Cerny V, Coats TJ, Duranteau J, Fernandez-Mondejar $\mathrm{E}$, et al. Management of bleeding and coagulopathy following major trauma: an updated European guideline. Crit Care. 2013;17:R76.

35. Ertel W, Keel M, Eid K, Platz A, Trentz O. Control of severe hemorrhage using C-clamp and pelvic packing in multiply injured patients with pelvic ring disruption. J Orthop Trauma. 2001;15:468-74.

36. Eastridge BJ, Salinas J, Wade CE, Blackbourne LH. Hypotension is $100 \mathrm{~mm}$ $\mathrm{Hg}$ on the battlefield. Am J Surg. 2011;202:404-8.

37. Edelman DA, White MT, Tyburski JG, Wilson RF. Post-traumatic hypotension: should systolic blood pressure of 90-109 mmHg be included? Shock. 2007; 27:134-8.

\section{Publisher's Note}

Springer Nature remains neutral with regard to jurisdictional claims in published maps and institutional affiliations.

\section{Ready to submit your research? Choose BMC and benefit from:}

- fast, convenient online submission

- thorough peer review by experienced researchers in your field

- rapid publication on acceptance

- support for research data, including large and complex data types

- gold Open Access which fosters wider collaboration and increased citations

- maximum visibility for your research: over $100 \mathrm{M}$ website views per year

At $\mathrm{BMC}$, research is always in progress.

Learn more biomedcentral.com/submissions 